\title{
Preventing catheter-associated infections in the Pediatric Intensive Care Unit: impact of an educational program surveying policies for insertion and care of central venous catheters in a Brazilian teaching hospital
}

\begin{abstract}
Objectives: To determine the impact of an educational program on the prevention of central venous catheter-related infections in a Brazilian Pediatric Intensive Care Unit. Patients and Methods: All patients admitted to the unit between February 2004 and May 2005 were included in the cohort study in a longitudinal assessment. An educational program was developed based on the Centers for Disease Control and Prevention recommendations for prevention of catheter-associated infections and was adapted to local conditions and resources after an initial observational phase. Incidence of catheter-associated infections was measured by means of on-site surveillance. Results: One hundred eighteen nosocomial infections occurred in 253 patients (46.6 infections per 100 admissions) and in 2,954 patient-days (39.9 infections per 1,000 patient-days). The incidence-density of catheter infections was 31.1 episodes per 1.000 venous central catheter-days before interventions, and 16.5 episodes per 1,000 venous central catheter-days afterwards (relative risk 0.53 [95\% CI 0.28-1.01]). Corresponding rates for exit-site catheter infections were 8.0 and 2.5 episodes per 1,000 venous central catheter-days [0.32 (0.07-1.49)], and the rates for bloodstream infections were 23.1 and 13.9 episodes per 1,000 venous central catheter-days, before and after interventions [0.61 (0.32-1.14)]. Conclusion: A prevention strategy targeted at the insertion and maintenance of vascular access can decrease rates of vascular-access infections in pediatric intensive care unit.
\end{abstract}

Keywords: catheterization, central venous; intensive care units; pediatric disease prevention.

\section{INTRODUCTION}

Although central venous catheters (CVC) are important for the management of critical patients, they are not without risks. CVC-associated infections (CVC-AI) are important health care-associated infections in pediatric intensive care units (PICU), with a relevant impact on morbidity and mortality, also increasing hospital costs. ${ }^{1-9}$ It has been estimated that infections occur in 3\% to $15 \%$ of all nontunneled inserted CVCs., ${ }^{40-12}$ In 2003, CVC-associated bloodstream infections (CVC-ABSI) were the most important nosocomial infection in our hospital, with a substantial incidence density rate (2.7 BSI per 1,000 venous central catheter-days), higher than that observed in the literature. Studies performed in adult intensive care units (ICU) have shown an important decrease in CVC-ABSI rates after educational intervention. However, little is known about pediatric settings. ${ }^{13-16}$ Given the importance of CVC-AI in PICU, the elevated rates in our PICU and the lack of literature relevant to this specific population, we initiated this study with the purpose of determining the impact of an educational program aiming at decreasing CVC-AI in a PICU of a developing country.

\section{METHODS}

\section{Setting}

This prospective interventional and educational study was conducted in an 8-bedded, medical-surgical PICU in an 800-bed teaching hospital of Universidade Federal de São Paulo, São Paulo, Brazil. All patients admitted to the unit for more than 24 hours between February and August 2004 (control period), September and October 2004 (intervention period) and November 2004 to May 2005 (post-intervention period) were prospectively evaluated and enrolled in the study.
Authors

Marcelo Luiz Abramczyk ${ }^{1}$ Werter B. Carvalho ${ }^{2}$ Eduardo A.S. Medeiros ${ }^{3}$

${ }^{1}$ Physician, Infectious Disease Pediatric Department, Universidade Federal de São Paulo (UNIFESP), SP, Brazil ${ }^{2}$ Full Professor, Pediatrics Department, Pediatric Intensive Care Unit, Universidade de São Paulo (USP), SP, Brazil

${ }^{3}$ Associate Professor, Hospital Infection Program, Division of Infectious Diseases, UNIFESP, SP, Brazil

Submitted on: 05/16/2011 Approved on: 06/15/2011

Correspondence to:

Marcelo Luiz Abramczyk Rua Napoleão de Barros, 690/20 - Vila Clementino 04024-062

São Paulo, SP

Brazil

mabramczyk@ig.com.br

We declare no conflict of interest.

(C2011 Elsevier Editora Ltda. All rights reserved. 


\section{Data collection}

Surveillance of nosocomial infection was based on the National Nosocomial Infection Surveillance System (NNISS), used in the unit since 2000, and was overseen by an infectious diseases pediatrician, who visited the unit daily during the study period.

\section{Description of the intervention}

The intervention period was implemented over a twomonth period and consisted of reviewing and updating unit policies and procedures concerning the insertion and maintenance of nontunneled CVC, based on Centers for Disease Control and Prevention (CDC)/Healthcare Infection Control Practices Advisory Committee (HIPAC) recommendations. ${ }^{17,18}$

Didactic lectures, totaling 6 hours, were given to physicians, fellows and nursing staff of the unit using a slide show. The most important messages were: (I) catheters should be inserted using maximal barrier recommendations; (II) all inserted catheters should be removed as soon as possible; (III) hub connection disinfection with $70 \%$ alcohol before and after manipulation; (IV) site insertion CVC should be protected with impermeable plastic during bath; (V) fundamental cooperation of all unit members. No preferential site of insertion was recommended.

PVPI was used to prepare the skin for insertion in pre-interventional and post-intervention phases, because chlorexidine was not standardized in the hospital during the study period.

\section{Definition}

CVC-AI were defined according to the CDC criteria of $1988 .{ }^{19}$ Exit site infections were defined as erythema, tenderness, induration or purulence affecting 2 $\mathrm{cm}$ of the skin at the exit site of the catheter. Primary bloodstream infections were defined as bacteraemia (or fungaemia), for which there was no documented distal source, and included infections resulting from insertion of a central intravenous line. The infection was categorized either as microbiologically documented or as clinical sepsis.

Infections were regarded as ICU acquired infections if they occurred during PICU stay or within 48 hours of discharge from the unit.

The presence of bacteremia was defined as the isolation of a pathogen from a blood culture of a patient with symptoms suggestive of infection. For patients with blood cultures from which coagulase-negative staphylococci were isolated, diagnosis of bacteremia required at least two positive blood cultures growing the same organism; for patients with clear evidence of sepsis and no other explanation for their symptoms except isolation of coagulase-negative staphylococci from a blood culture, a single positive blood culture result was considered sufficient for the diagnosis of bacteremia.

Patients having only totally implantable ports or hemodialysis catheters were excluded from the analyses.

\section{Analysis data}

Data were analyzed using STATA Version 7.0. The incidence rate of CVC-ABSI, CVC-site insertion and CVC-AI was calculated and the relative risk (RR) in the postinterventional period compared with the pre-interventional period was determined. A $95 \%$ confidence interval (CI) that did not include 1 and p-values $<0.05$ were considered statistically significant.

\section{RESULTS}

During the study period, 255 patients and 2,954 patientdays were screened. Patient characteristics are shown in Tables 1 and 2.

Pre-interventional and post-interventional groups were homogenous for the baseline variables studied, except for the use of immunosuppressive agents. In post-hoc analyses of risk factors for CVC-AI, immunosuppressive agents were not found to be a risk factor.

The rates of nosocomial infection (NI) were 44.4 $\mathrm{NI} / 1,000$ patient-days, $33.2 \mathrm{NI} / 1,000$ patient-days and $38.2 \mathrm{NI} / 1,000$ patient-days, during pre-intervention, intervention and post-intervention phases, respectively.

Two hundred and thirty-five CVC and 1,861 central venous catheter-days were evaluated, of which $18.7 \%$ had at least one associated infection. Device utilization was $63 \%$, without any significant changes during the study.

We identified 44 CVC-associated infections during pre-intervention and post-intervention phases. Table 3 shows the incidence density of catheter infections at 31.1 episodes per 1,000 venous central catheter-days before interventions and 16.5 episodes per 1,000 venous central catheter-days after interventions [RR 0.53 (95\% CI 0.28 1.01)]. Corresponding rates for exit-site catheter infections were 8 and 2.5 episodes per 1,000 venous central catheter-days, respectively [0.32 (95\% CI 0.07-1.49)], and the rates for bloodstream infections were 23.1 and 13.7 episodes per 1,000 venous central catheter-days, before and after intervention [0.61 (95\% CI 0.32-1.14)]. Incidence density rates observed are shown in Table 3 . After the intervention the density of CVC-AI dropped to $47 \%$ ( $\mathrm{p}=0.051$ ).

The distribution of pathogens was not different when comparing pre- and post-interventional phases (Table 4). Coagulase-negative Staphylococcus (CNS) was the most common pathogen identified. Gram-negative microorganisms were the most prevalent in the unit.

No changes in the unit characteristics were observed throughout the study period. 
Table 1. Characteristics of the patients enrolled in the study

\begin{tabular}{|c|c|c|c|c|}
\hline & \multicolumn{3}{|c|}{ Phases } & \multirow[b]{2}{*}{ p-value } \\
\hline & $\begin{array}{c}\text { Pre-intervention } \\
\text { phase }\end{array}$ & $\begin{array}{l}\text { Intervention } \\
\text { phase }\end{array}$ & $\begin{array}{c}\text { Post-intervention } \\
\text { phase }\end{array}$ & \\
\hline \multicolumn{5}{|l|}{ Gender } \\
\hline Female & 51 (48.6\%) & $10(40.0 \%)$ & $46(39.7 \%)$ & \multirow{2}{*}{0.383} \\
\hline Male & $54(51.4 \%)$ & $15(60.0 \%)$ & $70(60.3 \%)$ & \\
\hline Years (months) & $26.5(0-158)$ & $54.0(1-157)$ & $15.5(0-190)$ & 0.371 \\
\hline \multicolumn{5}{|l|}{ Parenteral nutrition } \\
\hline Yes & $15(14.2 \%)$ & $2(7.4 \%)$ & $22(18.3 \%)$ & \multirow{2}{*}{0.371} \\
\hline No & $91(85.8 \%)$ & $25(92.6 \%)$ & $98(81.7 \%)$ & \\
\hline \multicolumn{5}{|l|}{ Immunosuppression } \\
\hline Yes & 55 (51.9\%) & $15(55.6 \%)$ & $43(35.8 \%)$ & \multirow{2}{*}{0.026} \\
\hline No & $51(48.1 \%)$ & $12(44.4 \%)$ & $77(64.2 \%)$ & \\
\hline \multicolumn{5}{|l|}{ Outcome } \\
\hline Discharge & 99 (93.4\%) & $23(85.2 \%)$ & 106 (90.0\%) & \multirow{2}{*}{0.374} \\
\hline Death & 7 (6.6\%) & $4(14.8 \%)$ & 12 (10.0\%) & \\
\hline \multicolumn{5}{|c|}{ Death during hospital stay } \\
\hline Yes & $25(24.3 \%)$ & $5(19.2 \%)$ & 25 (22.1\%) & \multirow{2}{*}{0.907} \\
\hline No & $76(73.8 \%)$ & $21(80.8 \%)$ & $87(77.0 \%)$ & \\
\hline Transfer & $2(1.9 \%)$ & - & $1(0.9 \%)$ & \\
\hline Hospital stay (days) & $6.0(1-180)$ & $5.5(1-188)$ & $5.0(1-47)$ & 0.159 \\
\hline PIM II* & $\begin{array}{c}2.58 \\
(0.06-50.86) \\
\end{array}$ & $\begin{array}{c}3.10 \\
(0.22-58.15)\end{array}$ & $\begin{array}{c}1.85 \\
(0.08-38.47) \\
\end{array}$ & 0.203 \\
\hline \multicolumn{5}{|l|}{ Nosocomial infection } \\
\hline Yes & 37 (34.9\%) & $5(18.5 \%)$ & 32 (26.7\%) & \multirow{2}{*}{0.171} \\
\hline No & $69(65.1 \%)$ & $22(81.5 \%)$ & $88(73.3 \%)$ & \\
\hline \multicolumn{5}{|c|}{$\begin{array}{l}\text { Central venous catheter } \\
\text { associated infection }\end{array}$} \\
\hline Yes & 20 (18.9\%) & $3(11.1 \%)$ & $13(10.8 \%)$ & \multirow{2}{*}{0.228} \\
\hline No & $86(81.1 \%)$ & $24(88.9 \%)$ & 107 (89.2\%) & \\
\hline \multicolumn{5}{|c|}{ Central venous catheter } \\
\hline Yes & $70(66.0 \%)$ & 17 (63.0\%) & 77 (64.2\%) & \multirow{2}{*}{0.936} \\
\hline No & 36 (34.0\%) & $10(37.0 \%)$ & 43 (35.8\%) & \\
\hline
\end{tabular}

p < 0.05; *Pediatric Index of Mortality II (20).

\section{DISCUSSION}

Educational intervention is recommended by the BSI-CVC guidelines of the Infectious Disease Society of America to reduce $\mathrm{CVC}$-BSI rates. Apart from the fact that the literature shows an important drop in CVC-AI rates after implementation of educational programs in adults ICU, ${ }^{13-16}$ there is little information concerning PICU. This innovative study demonstrates the importance of an educational program as a tool to decrease CVC-AI in PICU. The decrease in CVC-AI seen in our study is similar to the $40 \%$ to $60 \%$ decrease obtained in adult ICUs using a similar approach. ${ }^{13-16}$ Bhutta et al. ${ }^{20}$ showed significant decreases in rates of bloodstream infections associated with catheters after the implementation of a similar educational program. Annual rates with CVC 
Table 2. Underlying diseases responsible for patient's hospitalization in the Pediatric Intensive Care Unit

\begin{tabular}{lcc}
\hline & $\mathbf{n}$ & $\mathbf{\%}$ \\
\hline Surgical & 65 & 25.7 \\
Cardiac & 13 & 5.1 \\
Neurosurgical & 7 & 2.8 \\
Abdominal surgery & 27 & 10.7 \\
Others & 18 & 7.1 \\
\hline No surgical & 188 & 74.3 \\
No chronic disease & 26 & 10.3 \\
Pulmonary disease & 18 & 7.1 \\
Intestinal disease & 22 & 8.7 \\
Neurological disease & 38 & 15.0 \\
Nonsurgical cardiac disease & 18 & 7.1 \\
Renal disease & 17 & 6.7 \\
AIDS & 2 & 0.8 \\
Hematological disease & 6 & 2.4 \\
Syndrome disorder & 22 & 8.7 \\
Trauma & 8 & 3.2 \\
Others & 11 & 4.3 \\
\hline Total & 253 & 100 \\
\hline
\end{tabular}

from 9.7/1,000 days in 1997 to 3.0/1,000 days in 2005, which translates to a relative risk reduction of $75 \%$ (95\% CI 35 to $126 \%$ ), an absolute risk reduction of $6 \%$ (95\% CI 2 to $10 \%)$ and a treatment number of 16 (195\% CI 0 to 35$)$.

The incidence density of catheter infections decreased substantially from 31.1 to 16.5 episodes per 1,000 venous central catheter-days [0.53 (95\% CI 0.28-1.01)] due to a decreased incidence of exit-site catheter infections (8.0 to 2.5 episodes per 1,000 venous central catheter-days) and bloodstream infections (23.1 to 13.9 episodes per 1,000 venous central catheter-days).

There was no decrease in mortality and number of days spent in hospital between pre and post-intervention phases.

Decreasing the rate of CVC-AI is an important focus for quality improvement in a critical-care setting.

An important component to the success of this study was the strong support received from the medical and nursing team of the unit.

A potential limitation to this study was the use of a before and after study design, but during the study period there was no alteration in the characteristics of the unit or in clinical or laboratory diagnosis. The patients in the pre- and postintervention period were comparable in almost all measured variables, including risk factors for CVC-AI, except for the use of immunosuppressive agents, which was greater during the pre-interventional phase. Nonetheless, we performed a risk factor analysis for $\mathrm{CVC}-\mathrm{AI}$, and the use of immunosuppressive agents was not significant.

Table 3. Incidence density rates during pre-intervention and post-intervention phases

\begin{tabular}{|c|c|c|c|c|c|c|c|}
\hline & \multicolumn{2}{|c|}{$\begin{array}{c}\text { Pre-intervention } \\
\text { phase }\end{array}$} & \multicolumn{2}{|c|}{$\begin{array}{c}\text { Post-intervention } \\
\text { phase }\end{array}$} & \multirow[b]{2}{*}{$\begin{array}{c}\text { Density } \\
\text { rates ratio }\end{array}$} & \multirow[b]{2}{*}{ IC $95 \%$} & \multirow[b]{2}{*}{ p-value } \\
\hline & $\mathbf{n}$ & $\begin{array}{c}\text { Incidence } \\
\text { density rates }\end{array}$ & $\mathbf{n}$ & $\begin{array}{c}\text { Incidence } \\
\text { density rates }\end{array}$ & & & \\
\hline Bloodstream infection & 23 & 23.1 & 11 & 13.9 & 0.61 & {$[0.32-1.14]$} & 0.166 \\
\hline Insertion site infection & 8 & 8.0 & 2 & 2.5 & 0.32 & [0.07-1.49] & 0.124 \\
\hline $\begin{array}{l}\text { Central venous catheter } \\
\text { associated infection }\end{array}$ & 31 & 31.1 & 13 & 16.5 & 0.53 & {$[0.28-1.01]$} & 0.051 \\
\hline
\end{tabular}

Table 4. Microbiology of central venous catheter associated infections

\begin{tabular}{lccc}
\hline Microorganisms & Pre-intervention phase & Intervention phase & Post-intervention phase \\
\hline Gram-negatives & $8(57.1 \%)$ & $1(100.0 \%)$ & $4(57.1 \%)$ \\
\hline Gram-positives & $4(28.6 \%)$ & $0(0 \%)$ & $2(28.6 \%)$ \\
\hline Yeasts & $2(14.3 \%)$ & $0(0 \%)$ & $1(14.3 \%)$ \\
\hline Total & $14(100.0 \%)$ & $1(100.0 \%)$ & $7(100.0 \%)$
\end{tabular}


Markers of changes in the caretaking process, like systematic observation of CVC insertion and care techniques as well as the care and manipulation of CVC, could not be collected. However, the profound involvement of the unit staff and the presence of a specific professional throughout the study period probably minimized this possibility.

We developed an effective educational strategy for the unit staff at minimal cost by using evidence-based guidelines for the proper insertion and care of CVC in a PICU of a developing country hospital, which resulted in a reduction of CVC-AI rates. We believe that our findings may be applicable to other PICU.

\section{REFERENCES}

1. Abramczyk ML, Carvalho WB, Carvalho ES, et al. Nosocomial infection in a developing country. Braz J Infect Dis. 2003; 7:375-80.

2. Armenian SH, Singh J, Arrieta AC. Risk factors for mortality resulting from bloodsstream infections in a pediatric intensive care unit. Pediatric Infect Dis J. 2005; 24:309-14.

3. Arnow PM, Quimisong EM, Beach M. Consequences of intravascular catheters sepsis. Clin Infect Dis. 1993; 16:778-84.

4. Arruda E, Marinho IS, Rodrigues E, et al. Central venous cathe Ater-related infections in intensive care units. Braz J Infect Dis. 1997; 1:182-5.

5. Ashkenazi S, Leibovic L, Samra Z, et al. Risk factors for mortality due to bacteremia and fungemia in childhood. Clin Infect Dis. 1992; 14:949-51.

6. Elward AM, Hollenbeak CS, Warren DK, et al. Attributable cost of nosocomial primary bloodstream infection in peditric intensive care unit patients. Pediatrics. 2005; 115:868-72.

7. Richards MJ, Edwards JR, Culver DH, et al. Nosocomial infections in pediatric intensive care units in the United States. Pediatrics. 1999; 103:e39.

8. Urrea M, Pons M, Serra M, et al. Prospective incidence study of nosocomial infections in a pediatric intensive care unit. Pediatric Infect Dis J. 2003; 22:490-4.
9. Yogorav JS, Elward AM, Fraser VJ. Rate, risk factors, and outcome of nosocomial primary bloodstream infection in a pediatric intensive care unit. Pediatrics. 2002; 110:481-5.

10. Hashal VL. Intravenous catheters and infection. Surg Clin North Am. 1972; 52:1407-7.

11. Jong PCM, Von Meyenfeldt MR, Rouflart M, et al. Complications of central venous catheterization of the subclavian vein: the influence of a parenteral nutrition team. Acta Anaesth Scand. 1985; suppl81:48-52.

12. Safdar N, Maki DG. The pathogenesis of catheter-related bloodstream infection with noncuffed short-term central venous catheters. Intensive Care Med. 2004; 30:62-7.

13. Eggimann $P$, Harbarth $S$, Constantin $M N$, et al. Impact of a prevention strategy target at vascular-access care on incidence of infections acquired in intensive care. Lancet. 2000; 355:1864-68.

14. Lobo RD, Levin AS, Gomes LMB, et al. Impact of an educational program and policy changes on decreasing catheter-associated bloodstream infections in a medical intensive care unit in Brazil. Am J Infect Control. 2005; 33:83-7.

15. Parras F, Ena J, Bouza E, et al. Impact educational program for the prevention of colonization of intravascular catheters. Infect Control Hosp Epidemiol. 1994; 15:239-42.

16. Warren DK, Zack JE, Cox MJ, et al. An educational intervention to prevent catheter-associated bloodstream infections in a nonteaching, community medical center. Crit Care Med. 2003; 31:1959-63.

17. Mermel LA, Barry MF, Sheretz RJ, et al. Guideline for the management of intravascular catheter-related infections. Infect Control Hosp Epidemiol. 2001; 22:222-42.

18. O'Grady NP, Alexander M, Dellinger P, et al. The Healthcare Infection Control Practices Advisory Committee. Guidelines for the prevention of intravascular catheter-related infections. Infect Control Hosp Epidemiol. 2002; 23:759-69.

19. Garner JS, Jarvis WR, Emori TG, et al. CDC definitions for nosocomial infections, 1988. J Infect Control. 1988; 16:128-40.

20. Bhutta A, Gilliam C, Honeycutt M, et al. Reduction of bloodstream infections associated with catheters in paediatric intensive care unit: stepwise approach. BMJ. 2007; 334:362-5. 